\title{
$\beta$-alanine supplementation improves isometric endurance of the knee extensor muscles
}

\author{
Craig Sale ${ }^{1 *}$, Chester A Hill ${ }^{2}$, James Ponte ${ }^{3}$ and Roger C Harris $^{4}$
}

\begin{abstract}
Background: We examined the effect of four weeks of $\beta$-alanine supplementation on isometric endurance of the knee extensors at $45 \%$ maximal voluntary isometric contraction (MVIC).

Methods: Thirteen males (age $23 \pm 6$ y; height $1.80 \pm 0.05 \mathrm{~m}$; body mass $81.0 \pm 10.5 \mathrm{~kg}$ ), matched for presupplementation isometric endurance, were allocated to either a placebo $(n=6)$ or $\beta$-alanine $\left(n=7 ; 6.4 \mathrm{~g} \cdot \mathrm{d}^{-1}\right.$ over 4 weeks) supplementation group. Participants completed an isometric knee extension test (IKET) to fatigue, at an intensity of $45 \% \mathrm{MVIC}$, before and after supplementation. In addition, two habituation tests were completed in the week prior to the pre-supplementation test and a further practice test was completed in the week prior to the post-supplementation test. MVIC force, IKET hold-time, and impulse generated were recorded.
\end{abstract}

Results: IKET hold-time increased by $9.7 \pm 9.4 \mathrm{~s}(13.2 \%)$ and impulse by $3.7 \pm 1.3 \mathrm{kN} \cdot \mathrm{s}^{-1}$ (13.9\%) following $\beta$-alanine supplementation. These changes were significantly greater than those in the placebo group (IKET: $t_{(11)}=2.9$, $p \leq 0.05$; impulse: $\left.t_{(11)}=3.1, p \leq 0.05\right)$. There were no significant changes in MVIC force in either group.

Conclusion: Four weeks of $\beta$-alanine supplementation at $6.4 \mathrm{~g} \cdot \mathrm{d}^{-1}$ improved endurance capacity of the knee extensors at $45 \%$ MVIC, which most likely results from improved $\mathrm{pH}$ regulation within the muscle cell as a result of elevated muscle carnosine levels.

Keywords: $\beta$-alanine, Carnosine, Isometric endurance, Intramuscular buffering

\section{Background}

High-intensity exercise is associated with the formation and net accumulation of carboxylic acid groups, principally in the form of the lactate anion ( $\left.\mathrm{Lac}^{-}\right)$. Lac production accounts for the generation of $94 \%$ of the hydrogen cation $\left(\mathrm{H}^{+}\right)$concentration in skeletal muscle [1]. Accumulation of $\mathrm{H}^{+}$, as a result of high-intensity exercise, may lead to a decline in intracellular $\mathrm{pH}$ from around 7.0 at rest [2] to as low as 6.0 [3]. $\mathrm{H}^{+}$accumulation may contribute to fatigue by interfering with several metabolic processes affecting force production [4]. More specifically, the accumulation of $\mathrm{H}^{+}$in skeletal muscle disrupts the recovery of phosphorylcreatine [5] and its role as a temporal buffer of ADP accumulation [6,7], inhibits glycolysis [8] and disrupts functioning of the muscle contractile machinery $[9,10]$.

\footnotetext{
* Correspondence: craig.sale@ntu.ac.uk

${ }^{1}$ Biomedical, Life and Health Sciences Research Centre, Nottingham Trent University, Clifton Lane, Nottingham NG11 8NS, UK

Full list of author information is available at the end of the article
}

The extent of the decrease in intracellular $\mathrm{pH}$ with the production of $\mathrm{H}^{+}$during exercise is mediated by intramuscular buffers and secondarily by $\mathrm{H}^{+}$transport from muscle. Physicochemical buffers need to be present in high concentrations in the muscle and also require a $\mathrm{pKa}$ that is within the exercise-induced $\mathrm{pH}$ transit range. Carnosine ( $\beta$-alanyl-L-histidine) is a cytoplasmic dipeptide found in high concentrations in skeletal muscle [11] and has a pKa of 6.83 for the imidazole ring, which makes it a suitable buffer over the physiological $\mathrm{pH}$ range $[12,13]$. Carnosine is formed by bonding histidine and $\beta$-alanine in a reaction catalysed by carnosine synthase, although, in humans, formation of carnosine in the skeletal muscle is limited by the availability of $\beta$ alanine [14].

Data from a recent meta-analysis [15] provides support for the assertion that the main mechanism supporting an effect of increased muscle carnosine on exercise performance and capacity is through an increase in intramuscular buffering capacity. Other studies also provide some indirect evidence to support this role [16,17],

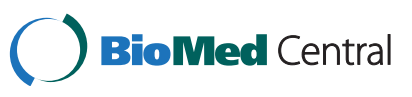


although this is by no means the only purported physiological role for carnosine that could influence exercise performance and capacity (for review see [18]).

Despite the role played by intramuscular buffers, $\mathrm{pH}$ will still fall concomitant with $\mathrm{Lac}^{-}$accumulation. As a result, it is vital to transport $\mathrm{H}^{+}$and $\mathrm{Lac}^{-}$out of the muscle cell to prevent further reductions in intracellular $\mathrm{pH}$, to reduce cellular concentrations of $\mathrm{Lac}^{-}$and allow extracellular buffers to assist in acid-base regulation. During dynamic exercise, transport of $\mathrm{H}^{+}$out of the muscle cell provides the main control over intracellular $\mathrm{pH}$, although physicochemical buffers and, to a lesser extent, metabolic buffers provide the first line of defence. However, under conditions where muscle blood flow is occluded, physicochemical buffers provide the only defence against local changes in $\mathrm{pH}$.

As such, an isometric exercise model provides a suitable means to further test the hypothesis that an increase in muscle carnosine content, following supplementation with $\beta$-alanine, improves exercise capacity and performance as a result of enhanced muscle buffering. Isometric contractions at around 15-20\% of maximal voluntary isometric contraction (MVIC) can result in increased intramuscular pressures that are sufficient to reduce muscle blood flow $[19,20]$. However, muscle blood flow is stopped completely at higher intensities $[19,20]$, with the result that the muscle acts as a closed system and the active muscle fibres are solely dependent upon anaerobic energy provision [21]. Isometric endurance hold time is dependent upon the intensity of the muscle contraction with higher percentages of MVIC causing shorter hold times [22]. At fatigue, the maximal accumulation of $\mathrm{Lac}^{-}$in the knee extensor muscles, and therefore decrement in muscle $\mathrm{pH}$, is caused by a moderate rate of lactate production $\left(\sim 1.1 \mathrm{mmol} \cdot \mathrm{kg}^{-1} \mathrm{dm} \cdot \mathrm{s}^{-1}\right)$ accumulated over a moderate time period. The optimal exercise intensity to accumulate lactate is around $45 \%$ of MVIC [23]. The Rohmert equation [22] predicts that a constant isometric contraction of the knee extensors will fail to maintain $45 \%$ MVIC after approximately $78 \mathrm{~s}$ [24].

Therefore, we aimed to examine the effect of $\beta$-alanine supplementation on isometric endurance of the knee extensor muscles at $45 \%$ of MVIC. Our hypothesis was that isometric hold times at $45 \%$ MVIC would be $78 \mathrm{~s}$ before supplementation and that these hold times would be increased with $\beta$-alanine but not with placebo.

\section{Method}

Participants

Sixteen physically active males volunteered and were split into a $\beta$-alanine and a placebo group. However, 3 participants dropped out of the study ( 2 from the placebo group and 1 from the $\beta$-alanine group) due to sports related injuries sustained during the period of supplementation. As a result, only thirteen participants completed both trials with 6 and 7 being supplemented with placebo and $\beta$-alanine, respectively (Table 1). All participants were considered healthy according to a health screening questionnaire and the health screening procedure was repeated prior to each laboratory visit to ensure the health status of the participants had not changed. Participants had not taken any supplement in the 3 months prior to the study and had not supplemented with $\beta$-alanine for at least 6 months. Participants were also requested to maintain similar levels of physical activity and dietary intake for the duration of the study and compliance with this request was verbally confirmed with participants prior to commencement of the study. None of the participants were vegetarian and would have consumed small amounts of $\beta$-alanine in their diet, typically 50 to $400 \mathrm{mg}$ per day. The study was approved by the institutions Ethical Advisory Committee and all participants provided informed consent.

\section{Experimental design}

Participants completed a total of five isometric knee extension tests (IKET), involving chiefly the m. quadriceps femoris, with the largest contribution to force production coming from the $m$. vastus lateralis, to fatigue at an intensity of $45 \%$ of MVIC force. Two habituation tests (the coefficient of variation [CV] between the two habituation tests was $5.5 \%$ for impulse and $7.0 \%$ for isometric hold time) were completed in the week prior to the pre-supplementation test. A further test was performed during week 4 as a practice post-test, with the post-supplementation test being performed at the end of the 4 week supplementation period. Testing sessions were separated by a minimum of $72 \mathrm{~h}$ and participants were instructed not to perform any vigorous exercise in the $48 \mathrm{~h}$ prior to each session.

Participants were supplemented with either $6.4 \mathrm{~g} \cdot \mathrm{d}^{-1}$ $\beta$-alanine $\left(\right.$ CarnoSyn $^{\text {tw }}$, NAI, USA) or an equivalent amount of placebo (maltodextrin; NAI, USA). Participants were first matched in to pairs based upon their pre-supplementation isometric endurance. The $\beta$-alanine dosing regimen consisted $800 \mathrm{mg}$ tablets eight times per day at 2 hour intervals or the same regimen for placebo (maltodextrin) tablets. Participants completed a

Table 1 Participant characteristics

\begin{tabular}{llrccc}
\hline & & $\begin{array}{l}\text { Age } \\
(\mathbf{y})\end{array}$ & $\begin{array}{l}\text { Height } \\
(\mathbf{m})\end{array}$ & \multicolumn{2}{c}{ Body Mass $\mathbf{( k g )}$} \\
\hline $\boldsymbol{\beta}$-alanine & Mean & 24 & 1.81 & Week 0 & Week 4 \\
$\mathbf{n = 7}$ & SD & 7 & 0.04 & 10.9 & 81.9 \\
Placebo & Mean & 21 & 1.79 & 80.3 & 10.8 \\
$\mathbf{n = 6}$ & SD & 4 & 0.06 & 10.9 & 11.2 \\
\hline
\end{tabular}


supplementation $\log$ to verify compliance, with the degree of compliance being reported at $>95 \%$ in both groups. Supplementation with $\beta$-alanine at this level has consistently been shown to increase muscle carnosine concentrations by around $60 \%[14,16]$, with others reporting no non-responders to $\beta$-alanine supplementation $[16,25,26]$. Overall increases have been shown to be between $40 \%$ and $80 \%$ depending upon dose (between 3.2 and $6.4 \mathrm{~g} \cdot \mathrm{d}^{-1}$ ) and duration of administration (between 4 and 10 weeks).

\section{Experimental procedure}

Upon entering the laboratory, participants were secured in an isometric chair in the sitting position with the back-to-thigh angle and the thigh-to-lower leg angle both set at $90^{\circ}$. All tests were conducted using the nondominant leg. Force output was measured by a strain gauge attached to the lower leg of the participant just above the ankle with kevlar webbing. The strain gauge was attached to a Powerlab/400 system (ADI instruments, UK) connected to a personal computer.

Participants were initially requested to perform three MVICs of the knee extensor muscles separated by $90 \mathrm{~s}$ recovery. Participants were then requested to begin the IKET, which involved holding $45 \%$ of their highest MVIC force until volitional exhaustion. Participants were deemed to have started the IKET once force output had reached $95 \%$ of the target force output for more than $1 \mathrm{~s}$. Fatigue was quantified as the point at which the participants force output fell below $95 \%$ of the target force for more than $1 \mathrm{~s}$. The frequency output of the strain gauge was amplified and quantified by the Powerlab/400 and converted to an instantaneous, visual representation of the force output on a computer screen. Participants were required to maintain force output, as close as possible, to the target force, which was indicated by a line superimposed upon the computer screen. In addition to this visual representation, participants were also given verbal feedback when their force output was "too high", "too low" or "on the line".

The time the contraction was held above $95 \%$ of target force (s) was recorded. From the force output data, the average force and $\mathrm{CV}$ about the average force were calculated. The impulse $(\mathrm{kN} \cdot \mathrm{s})$ was taken as the product of the average force $(\mathrm{N})$ and the duration of the contraction that was held above $95 \%$ of the target force (s). As force output was not controlled at exact levels during the IKET, with some variation possible in relation to the maintenance of the target force by the participant, we calculated the average force over a set time period, determined by the shortest hold time of either the preor post-supplementation IKET. The average force of the longer IKET was then calculated up to the time of the shorter IKET. This produced two impulse scores based upon the same time duration, which provided a means of assessing whether changes in average force may have resulted in an increase or reduction in the endurance time held. Importantly, the change in impulse (representative of average force in this case, since the time was the same) from pre- to post-supplementation in the $\beta$-alanine group $\left(+0.14 \pm 0.58 \mathrm{kN} \cdot \mathrm{s}^{-1}\right)$ was not significantly different from the change shown in the placebo group $\left(-0.13 \pm 0.58 \mathrm{kN} \cdot \mathrm{s}^{-1}\right)$.

\section{Statistical methods}

All data are presented as mean $\pm 1 \mathrm{SD}$, with statistical significance accepted at $p \leq 0.05$. To examine differences between the two treatment groups, delta values were calculated for each participant for all variables. Independent samples $t$-tests were used to assess differences in all variables between the two treatment groups. This was apart from comparing the actual endurance hold times to those predicted by the Rohmert equation [22] at 0 and 4 weeks. For this, a 3 way mixed model ANOVA was used: (actual hold time (independent measure) $\mathrm{x}$ predicted hold time (independent measure) $\mathrm{x}$ time (repeated measure)). CV and 95\% confidence limits were used to quantify the variability of dependent measures of the placebo group.

\section{Results}

\section{MVIC force and IKET}

Participants were instructed to hold the same absolute force output during the pre- and post-supplementation tests (45\% of pre-supplementation MVIC force). Delta values for the $\beta$-alanine group $(+0.3 \pm 1.0 \%)$, were not significantly different from the placebo group $(-0.1 \pm 1.4 \%)$. Fluctuations in force held during the $45 \%$ MVIC test were assessed by calculating the CV about the mean force held. In both the pre- and postsupplementation tests for both groups the CV was 3.9\%, with no significant differences between the two supplementation groups.

IKET hold times, pre- and post-supplementation are shown in Table 2. The $9.7 \pm 9.4 \mathrm{~s}$ gain $(+13.2 \%)$ in the $\beta$-alanine group was significantly higher $\left(t_{(11)}=2.9\right.$, $p<0.05)$ than the corresponding change in the placebo

Table 2 Mean \pm SD of endurance hold times for the $\beta$-alanine and placebo groups

\begin{tabular}{llllcc}
\hline & & $\begin{array}{l}\text { Pre } \\
\text { (s) }\end{array}$ & $\begin{array}{l}\text { Post } \\
\text { (s) }\end{array}$ & $\begin{array}{l}\text { Delta } \\
\text { (s) }\end{array}$ & $\begin{array}{l}\text { Change } \\
(\%)\end{array}$ \\
\hline $\boldsymbol{\beta}$-alanine & Mean & 76.9 & 86.6 & $9.7^{*}$ & $13.2^{*}$ \\
$\mathbf{n}=\mathbf{7}$ & SD & 19.5 & 21.9 & 9.4 & 14.3 \\
Placebo & Mean & 75.0 & 72.5 & -2.6 & -4.0 \\
$\mathbf{n = 6}$ & SD & 16.7 & 18.5 & 4.3 & 6.6 \\
\hline
\end{tabular}

* denotes a statistically significant difference from placebo at $p \leq 0.05$. 
group $(-2.6 \pm 4.3 \mathrm{~s})$. When examining the individual data (Figure 1), six out of seven participants showed improvements with $\beta$-alanine supplementation. When compared to the typical variance associated with the placebo group, five out of seven $\beta$-alanine supplemented participants showed improvements greater than the $+95 \%$ confidence limits associated with the placebo group (+5.9 and $-11.1 \mathrm{~s})$.

A premise of the study was that Lac plus pyruvate accumulation in muscle were greatest when isometric exercise was performed at $45 \%$ MVIC, with fatigue occurring after approximately $78 \mathrm{~s}$ [24]. Mean presupplementation IKET hold-times were within $4 \mathrm{~s}$ of those predicted by the Rohmert curve [22] and applied to the $m$. quadriceps femoris by [24]. There were no significant differences between the actual presupplementation endurance hold times and those predicted by the Rohmert curve in either the placebo or $\beta$-alanine groups.

\section{Impulse}

We calculated impulse values (IKET hold-time $\mathrm{x}$ actual, average force held) to account for participant dependent differences between the force outputs produced pre- and post-supplementation, which might make it a better indicator of performance change than IKET hold-time alone. Impulse values pre- and post-supplementation are shown in Table 3. The $3.7 \pm 1.3 \mathrm{kN} \cdot \mathrm{s}^{-1}$ gain $(+13.9 \%)$ in the $\beta$-alanine group was significantly different $\left(t={ }_{(11)}\right.$ $3.1, p<0.05)$ to the change in the placebo group

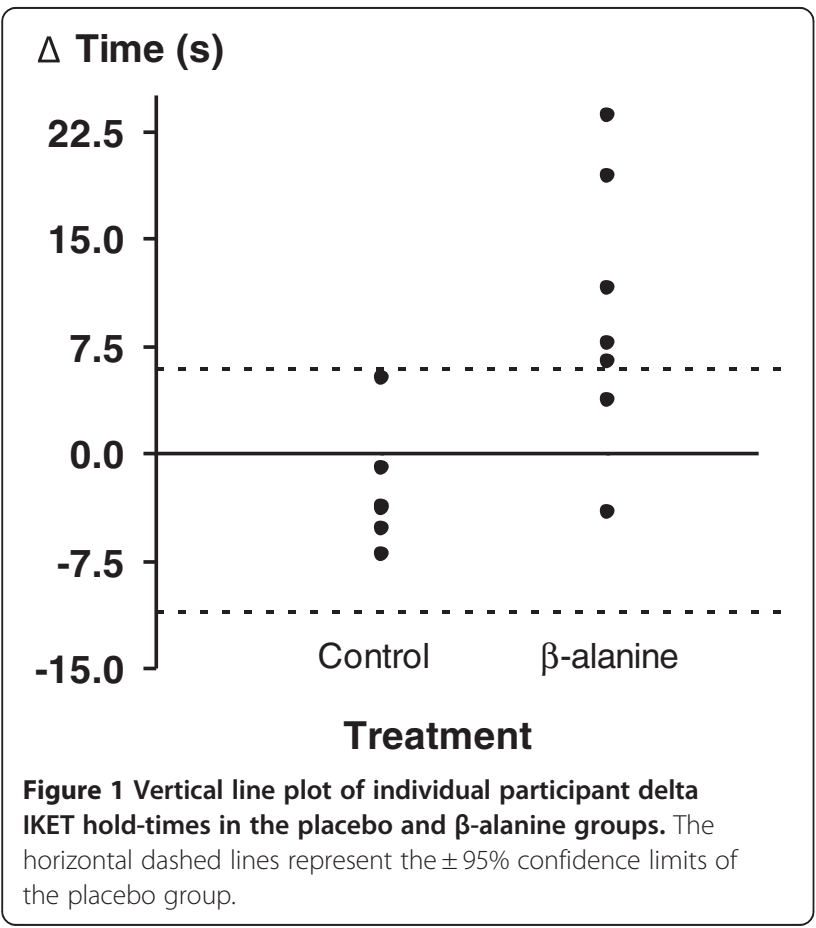

Table 3 Mean \pm SD of impulse data for the $\beta$-alanine and placebo groups

\begin{tabular}{llrrrr}
\hline & & $\begin{array}{l}\text { Pre } \\
\left(\mathbf{k N} \cdot \mathbf{s}^{-1}\right)\end{array}$ & \multicolumn{1}{c}{$\begin{array}{l}\text { Post } \\
\left(\mathbf{k N} \cdot \mathbf{s}^{-1}\right)\end{array}$} & $\begin{array}{l}\text { Delta } \\
\left(\mathbf{k N} \cdot \mathbf{s}^{-1}\right)\end{array}$ & $\begin{array}{l}\text { Change } \\
(\%)\end{array}$ \\
\hline -alanine & Mean & 26.0 & 29.7 & $3.7^{*}$ & $13.9^{*}$ \\
$\mathbf{n}=\mathbf{7}$ & SD & 7.7 & 9.2 & 3.4 & 14.5 \\
Placebo & Mean & 23.4 & 22.3 & -1.1 & -4.3 \\
$\mathbf{n}=\mathbf{6}$ & SD & 5.6 & 5.0 & 1.5 & 6.1 \\
\hline
\end{tabular}

* denotes a statistically significant difference from placebo at $\mathrm{p} \leq 0.05$.

$\left(-1.1 \pm 1.5 \mathrm{kN} \cdot \mathrm{s}^{-1}\right)$. When examining the individual data (Figure 2), six out of seven participants showed improvements with $\beta$-alanine supplementation. When compared to the typical variance associated with the placebo group, five out of seven $\beta$-alanine supplemented participants showed improvements greater than the $+95 \%$ confidence limits associated with the placebo group (+1.9 and $\left.-4.1 \mathrm{kN} \cdot \mathrm{s}^{-1}\right)$.

\section{Discussion}

In this study we show the effect of 4 weeks of $\beta$-alanine supplementation on isometric endurance of the knee extensors at 45\% MVIC and demonstrate a $13.2 \%$ increase in isometric endurance and a $13.9 \%$ increase in impulse. No changes were shown in MVIC force or equalized impulse in either group. As similar average forces were held by participants pre- and postsupplementation, there is evidence that changes in exercise capacity following $\beta$-alanine supplementation were

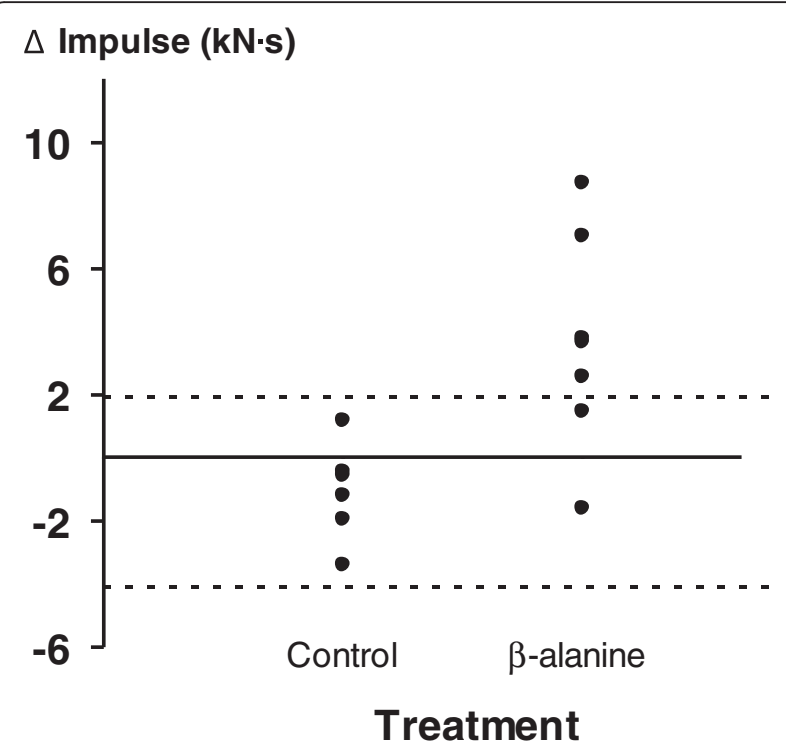

Figure 2 Vertical line plot of individual participant delta impulse values in the placebo and $\beta$-alanine groups.

The horizontal dashed lines represent the $\pm 95 \%$ confidence limits of the placebo group. 
related to changes in the capability of the muscle to endure sustained intense isometric exercise. Whilst not the focus of the current study, these results suggest a potential benefit of $\beta$-alanine supplementation for several real world applications where isometric exercise is performed (e.g., lifting and carrying, sailing and climbing/mountaineering among other things).

Importantly, endurance hold times for both treatment groups were not significantly different from values predicted by the Rohmert curve [22,24]. The maximal accumulation of lactate and pyruvate, and therefore $\mathrm{H}^{+}$ accumulation, is a function of isometric exercise intensity and occurs when MVIC is approximately $45 \%$ (when the endurance hold time is around $78 \mathrm{~s}$ ) [24]. From the data of Ahlborg et al. [24] we estimate that the increase in isometric endurance shown in the $\beta$-alanine group would have resulted in the additional accumulation of $\sim 10.7 \mathrm{mmol} \cdot \mathrm{kg}^{-1} \mathrm{dm} \mathrm{Lac}{ }^{-}$and $\mathrm{H}^{+}$in the muscle. The increase in $\mathrm{H}^{+}$is of the same order as the estimated increase in buffering capacity from the expected increase in muscle carnosine levels, brought about by the programme of $\beta$-alanine supplementation (i.e., $6.4 \mathrm{~g} \cdot \mathrm{d}^{-1}$ $\beta$-alanine or $179.2 \mathrm{~g}$ in total). From the data of Harris et al. [14] and Hill et al. [16], where participants were supplemented with $145.6 \mathrm{~g} \beta$-alanine over 4 weeks, we predict that the current supplementation regimen would result in an increase in carnosine in $\mathrm{m}$. vastus lateralis of $\sim 18 \mathrm{mmol} \mathrm{kg}^{-1}$ dry muscle, an increase of $\sim 70 \%$ from an assumed pre-supplementation level of $\sim 25 \mathrm{mmol} \cdot \mathrm{kg}^{-}$ ${ }^{1} \mathrm{dm}$. From the Henderson-Hasselbalch equation, which links $\mathrm{pKa}, \mathrm{pH}$ and metabolite concentration, an increase of $18 \mathrm{mmol} \mathrm{kg} \mathrm{dm}^{-1} \mathrm{dm}$ would increase buffering by $\sim 9.4 \mathrm{mEq} \mathrm{H} \mathrm{H}^{+} \cdot \mathrm{kg}^{-1} \mathrm{dm}$ over an assumed $\mathrm{pH}$ transit range of between 7.1 at rest and $\sim 6.0$ at fatigue [3]. Whilst these calculations are a useful way to provide some discussion around the link between $\mathrm{H}^{+}$production and the increase in buffering provided by the elevation in muscle carnosine, it must be noted that this is based upon assumptions relating to the level of increase in muscle carnosine and the exact $\mathrm{pH}$ transit range in this study, since muscle biopsy data were not obtained. This highlights a potential limitation of the current study and demonstrates the need for future work to repeat the current study with the addition of mechanistic information provided from muscle determinations of carnosine, $\mathrm{Lac}^{-}$and $\mathrm{pH}$.

Derave et al. [26] previously examined the effects of 4 weeks $\beta$-alanine supplementation at $4.8 \mathrm{~g} \cdot \mathrm{d}^{-1}$ on isometric muscle endurance of the knee extensors at, what was claimed to be, $45 \%$ MVIC in trained $400 \mathrm{~m}$ runners. In contrast to our results, Derave et al. [26] reported no significant effect of $\beta$-alanine on isometric hold-time. However, the pre-treatment times to fatigue reported by Derave et al. [26] were 175 and 201 seconds for the placebo and $\beta$-alanine groups, respectively, which brings into question the true intensity of the exercise used in their study given that the hold-time at $45 \%$ MVIC would be expected to be $\sim 80$ s [24]. Using the data of Ahlborg et al. [24], we estimate that the true intensity of the exercise in the Derave et al. [26] study was probably closer to $25 \%$ MVIC. At this exercise intensity it is likely that muscle blood flow would have been hampered but that some circulation would have been maintained enabling $\mathrm{H}^{+}$transport from muscle to occur. This would explain the lack of any significant effect of $\beta$-alanine supplementation in their study.

The $13.2 \%$ increase in IKET hold-time with $\beta$-alanine supplementation is comparable with the increases in exercise capacity shown with high intensity cycling following 4 weeks of $\beta$-alanine supplementation. In two different studies, increases in exercise capacity were $13.0 \%$ [16] and $14.6 \%$ [17], providing some evidence of a similar level of effect of $\beta$-alanine supplementation on exercise capacity across these studies. There is now increasing evidence to support a positive effect of $\beta$ alanine supplementation on high-intensity exercise capacity, mediated through an increase in muscle carnosine, which is further highlighted by a recent meta-analysis of the literature [15].

Whilst a role for carnosine as an intracellular buffer is undisputable, due to both its pKa of 6.83 and its location and concentration in muscle, other physiological roles of carnosine may also contribute to changes in exercise capacity during isometric knee extension exercise. Carnosine has been suggested to increase calcium ion $\left(\mathrm{Ca}^{2+}\right)$ sensitivity in muscle fibres $[27,28]$ and to improve sarcoplasmic reticulum function $[29,30]$, potentially augmenting force production and increasing work done. Both of these effects, however, might also be enhanced by improved $\mathrm{pH}$ regulation within the muscle cell $[31,32]$. Furthermore, neither of these physiological roles for carnosine have been shown in humans and the work cited above has been conducted in vitro. Lamont and Miller [28] showed that carnosine reduced the amount of $\mathrm{Ca}^{2+}$ required to produce half-maximum tension in chemically skinned cardiac and skeletal muscle and also reported an increase in maximal force production by different muscle types. They suggested that higher concentrations of carnosine, which are shown in fast twitch muscle fibres, might relate to an effect of enhanced $\mathrm{Ca}^{2+}$ sensitivity on muscle contractility in fibres capable of producing greater force. Dutka and Lamb [27] showed an increased $\mathrm{Ca}^{2+}$ sensitivity of the contractile apparatus, in a concentration-dependent manner, with the addition of carnosine to the cytoplasmic environment. The authors suggested that these results were due to the fact that carnosine sensitises the contractile apparatus to $\mathrm{Ca}^{2+}$, without causing additional release from the sarcoplasmic 
reticulum, thus increasing force production. Whilst the current evidence base for increased $\mathrm{Ca}^{2+}$ ion sensitivity in muscle fibres is restricted to in vitro work, it would be of interest to examine a possible effect in vivo.

The contribution of carnosine to intracellular buffering during isometric exercise might be related to the recruitment pattern of muscle fibres, since different concentrations of carnosine are reported in type I and II fibres $[33,34]$. Beltman et al. [35] showed that, after seven intermittent $1 \mathrm{~s}$ contractions, fibre type activation at 39\% MVIC differed between fibres types. Type I and IIa fibres were recruited at 39\% MVIC, whereas type IIx fibres were only recruited at $87 \%$ MVIC. Progressive shifts in phosphorylcreatine/creatine from low to high percentages of MVIC were greater in type I fibres compared to type IIa fibres, which in turn, were greater than in type IIx fibres, suggesting a progressive activation or rate coding of fibres [35]. However, this study did not examine fibre recruitment in contractions sustained to fatigue by which point, most likely, all fibre types would have been recruited. Of relevance to the issue of fibre involvement, we have previously shown that $\beta$-alanine supplementation increases carnosine to an equal extent in both type I and II muscle fibres in $m$. vastus lateralis [16,36].

In conclusion, four weeks of $\beta$-alanine supplementation at $6.4 \mathrm{~g} \cdot \mathrm{d}^{-1}$ improves endurance capacity of the knee extensors at $45 \%$ MVIC, which most likely results from improved $\mathrm{pH}$ regulation within the muscle cell as a result of elevated muscle carnosine levels.

\footnotetext{
Abbreviations

ADP: Adenosine-5'-diphosphate; ANOVA: Analysis of variance; $\mathrm{Ca}^{2+}$ : Calcium ion; CV: Coefficient of variation; $\mathrm{H}^{+}$: Hydrogen cation; IKET: Isometric knee extension test; Lac: Lactate anion; MVIC: Maximal voluntary isometric contraction.

\section{Competing interests}

We declare that we received $\beta$-alanine and maltodextrin supplies from NAI to undertake this study, though no additional funding was provided. $\mathrm{RCH}$ is retired and an independent paid consultant of NAI but undertook the study whilst the University of Chichester. RCH is named as an inventor on patents held by NAl and first filed, and is in receipt of other research grants for research on $\beta$-alanine awarded elsewhere.
}

\section{Author details}

${ }^{1}$ Biomedical, Life and Health Sciences Research Centre, Nottingham Trent University, Clifton Lane, Nottingham NG11 8NS, UK. ²Southern Cycle Coaching, Fareham, Hampshire, UK. ${ }^{3}$ University of Chichester, Chichester, West Sussex PO19 6PE, UK. ${ }^{4}$ Junipa Ltd, Newmarket, Suffolk, UK.

\section{Authors' contributions}

$\mathrm{RCH}$ first proposed the study and undertook an initial pilot investigation. All authors were responsible for the development of the final experimental design; $\mathrm{CS}$ and $\mathrm{RCH}$ were responsible for writing of the manuscript; $\mathrm{CAH}$ and $\mathrm{RCH}$ were responsible for data analysis; $\mathrm{CAH}$ and JP were responsible for data collection; CAH was responsible for reviewing drafts of the manuscript. All authors read and approved the final manuscript.

Received: 24 April 2012 Accepted: 30 May 2012

Published: 14 June 2012

\section{References}

1. Hultman E, Sahlin K: Acid-base balance during exercise. Exerc Sport Sci Rev 1980, 8:41-128.

2. Sahlin $\mathrm{K}$, Harris RC, Nylind B, Hultman E: Lactate content and $\mathrm{pH}$ in muscle obtained after dynamic exercise. Pflugers Archives 1976, 367:143-149.

3. Pan JW, Hamm JR, Hetherington HP, Rothman DL, Shulman RG: Correlation of lactate and $\mathrm{pH}$ in human skeletal muscle after exercise by $1 \mathrm{H}$ NMR. Magn Reson Med Sci 1991, 20:57-65.

4. Spriet LL, Lindinger MI, McKelvie RS, Heigenhauser GJF, Jones NL: Muscle glycogenolysis and $\mathrm{H}+$ concentration during maximal intermittent cycling. J App/ Physiol 1989, 66:8-13.

5. Harris RC, Edwards RHT, Hultman E, Nordesjo LO, Nylind B: The time course of phosphorylcreatine resynthesis during recovery of the quadriceps muscle in man. Pflugers Archives 1976, 367:137-142.

6. Sahlin K, Harris RC: The creatine kinase reaction: a simple reaction with functional complexity. Amino Acids 2011, 40:1363-1367.

7. Wallimann T, Tokarska-Schlattner M, Schlattner U: The creatine kinase system and pleiotropic effects of creatine. Amino Acids 2011, 40:1271-1296.

8. Trivedi $\mathrm{B}$, Daniforth $\mathrm{WH}$ : Effect of $\mathrm{pH}$ on the kinetics of frog muscle phosphofructokinase. J Biol Chem 1966, 241:4110-4112.

9. Donaldson SKB, Hermansen L: Differential direct effects of $\mathrm{H}+$ and $\mathrm{Ca} 2+$ - activated force of skinned fibres from the soleus, cardiac, adductor magnus muscle of rabbits. Pflugers Archive 1978, 376:55-65.

10. Fabiato A, Fabiato F: Effects of $\mathrm{pH}$ on the myofilaments and the sarcoplasmic reticulum of skinned cells from cardiac and skeletal muscles. J Physiol 1978, 276:233-235.

11. Mannion AF, Jakeman PM, Dunnett M, Harris RC, Willian PL: Carnosine and anserine concentrations in the quadriceptsfemoris muscle of healthy humans. Eur J Appl Physiol 1992, 64:47-50.

12. Bate-Smith EC: The buffering of muscle in rigour: protein, phosphate and carnosine. J Physiol 1938, 92:336-343.

13. Harris RC, Marlin DJ, Dunnett M, Snow DH, Hultman E: Muscle buffering capacity and dipeptide content in the thoroughbred horse, greyhound dog and man. Comp Physiol Biochem 1990, 97A:249-251.

14. Harris RC, Tallon MJ, Dunnett M, Boobis LH, Coakley J, Kim HJ, Fallowfield JL, Hill CA, Sale C, Wise JA: The absorption of orally supplied $\beta$-alanine and its effect on muscle carnosine synthesis in human vastus lateralis. Amino Acids 2006, 30:279-289.

15. Hobson RM, Saunders B, Ball G, Harris RC, Sale C: Effects of beta-alanine supplementation on exercise performance: a review by meta-analysis. Amino Acids 2012, 43:25-37.

16. Hill CA, Harris RC, Kim HJ, Harris BD, Sale C, Boobis LH, Kim CK, Wise JA: Influence of $\beta$-alanine supplementation on skeletal muscle carnosine concentrations and high intensity cycling capacity. Amino Acids 2007, 32:225-233.

17. Sale C, Saunders B, Hudson S, Wise JA, Harris RC, Sunderland CD: Effect of beta-alanine plus sodium bicarbonate on high-intensity cycling capacity. Med Sci Sports Exerc 2011, 43:1972-1978.

18. Sale C, Saunders B, Harris RC: Effect of beta-alanine supplementation on muscle carnosine concentrations and exercise performance. Amino Acids 2010, 39:321-333.

19. Bonde-Petersen F, Mork Al, Nielsen E: Local muscle blood flow and sustained contractions of human arm and back muscles. Eur J Appl Physiol 1975, 34:43-50.

20. Sjogaard G, Savard G, Juel C: Muscle blood flow during isometric activity and its relation to muscle fatigue. Eur J Appl Physiol 1988, 57:327-335.

21. De Ruitter CJ, Goudsmit JFA, Van Tricht JA, De Haan A: The isometric torque at which knee-extensor muscle reoxygenation stops. Med Sci Sports Exerc 2007, 39:443-452.

22. Rohmert W: Determination of the recovery pause for static work of man. Int Z Angew Physiol 1960, 18:123-164.

23. Harris RC: Muscle energy metabolism in man in response to isometric contraction: A biopsy study. Wales: M.Sc. thesis, University of Bangor; 1981.

24. Ahlborg B, Bergström J, Ekelund L, Guarnieri G, Harris RC, Hultman E, Nordesjö L: Muscle metabolism during isometric exercise performed at constant force. J Appl Physiol 1972, 33:224-228.

25. Baguet A, Reyngoudt H, Pottier A, Everaert I, Callens S, Achten E, Derave W Carnosine loading and washout in human skeletal muscles. J App/ Physiol 2009, 106:837-842. 
26. Derave W, Ozdemir MS, Harris RC, Pottier A, Reyngoudt H, Koppo K, Wise JA, Achten E: $\beta$-alanine supplementation augments muscle carnosine content and attenuates fatigue during repeated isokinetic contraction bouts in trained sprinters. J Appl Physiol 2007, 103:1736-1743.

27. Dutka TL, Lamb GD: Effect of carnosine on excitation-contraction coupling in mechanically-skinned rat skeletal muscle. J Muscle Res Cell Motil 2004, 25:203-213.

28. Lamont C, Miller DJ: Calcium sensitizing action of carnosine and other endogenous imidazoles in chemically skinned striated muscle. J Physiol 1992, 454:421-434.

29. Batrukova MA, Rubtsov AM: Histidine-containing dipeptides as endogenous regulators of the activity of sarcoplasmic reticulum Carelease channels. Biochim Biophys Acta 1997, 1324:142-150.

30. Roberts PR, Zaloga GP: Cardiovascular Effects of Carnosine. Biochem Mosc 2000, 65:856-861.

31. Katz AM: Contractile proteins of the heart. Physiol Rev 1970, 50:63-158.

32. Westerblad $\mathrm{H}$, Allen DG: The influence of intracellular $\mathrm{pH}$ on contraction, relaxation and $\left[\mathrm{Ca}^{2+}\right]$ in intact single fibres from mouse muscle. J Physiol 1993, 466:611-628.

33. Harris RC, Dunnett M, Greenhaff PL: Carnosine and Taurine contents in individual fibres of human vastuslateralis muscle. J Sport Sci 1998, 16:639-643.

34. Sewell DA, Harris RC, Marlin DJ, Dunnett M: Estimation of the carnosine content of different fibre types in the middle gluteal muscle of the thoroughbred horse. J Physiol 1992, 455:447-453.

35. Beltman JG, de Haan A, Haan H, Gerrits HL, van Mechelen W, Sargeant AJ: Metabolically assessed muscle fibre recruitment in brief isometric contractions at different intensities. Eur J Appl Physiol 2004, 92:485-492.

36. Kendrick IP, Kim HJ, Harris RC, Kim CK, Dang VH, Lam TQ, Bui TT, Wise JA: The effect of 4 weeks beta-alanine supplementation and isokinetic training on carnosine concentrations in type I and II human skeletal muscle fibres. Eur J Appl Physiol 2009, 106:131-138.

doi:10.1186/1550-2783-9-26

Cite this article as: Sale et al: $\beta$-alanine supplementation improves isometric endurance of the knee extensor muscles. Journal of the International Society of Sports Nutrition 2012 9:26.

\section{Submit your next manuscript to BioMed Central and take full advantage of:}

- Convenient online submission

- Thorough peer review

- No space constraints or color figure charges

- Immediate publication on acceptance

- Inclusion in PubMed, CAS, Scopus and Google Scholar

- Research which is freely available for redistribution 